\title{
Effects of context and individual predispositions on hypervigilance to pain-cues: an ERP study
}

\author{
This article was published in the following Dove Press journal: \\ Journal of Pain Research \\ II August 2015 \\ Number of times this article has been viewed
}

\section{Oliver Dittmar' \\ Corinna Baum ${ }^{1,2}$ \\ Raphaela Schneider ${ }^{\prime}$ \\ Stefan Lautenbacher'}

'Physiological Psychology, University of Bamberg, Bamberg, '2 Institute of Psychology, Technical University of Darmstadt, Darmstadt, Germany
Correspondence: Oliver Dittmar Physiological Psychology, University of Bamberg, Markusplatz 3, 96045 Bamberg, Germany

Tel $+4995 \mid 8631874$

Fax +49 95I 863I976

Email oliver.dittmar@uni-bamberg.de
Background: Hypervigilance to pain is the automatic prioritization of pain-related compared with other stimuli. The processing of threat information is influenced by negative contexts. Therefore, we intended to explore such context effects on hypervigilance to pain-cues, taking individual differences in self-reported vigilance to pain into consideration.

Methods: In all, 110 healthy subjects viewed task-irrelevant emotional facial expressions (anger, happy, neutral, and pain) overlaid in half of the trials with a fine grid. The instructed task was to indicate the presence/absence of this grid. A threatening context was established by applying electrical stimuli slightly below pain-threshold. Using scores of Pain Vigilance and Awareness Questionnaire, the sample was divided into high vs low pain vigilant subjects. Reaction times and event-related brain potentials were recorded.

Results: No distinct attentional processing of pain faces (based on the event-related brain potentials) was observed as a function of high levels of self-reported vigilance to pain and contextual threat induction. High pain vigilant subjects showed generally enhanced processing of emotional and neutral faces as indicated by parameters of early (early posterior negativity) and late (late positive complex) processing stages. This enhancement was abolished when electro-stimuli were presented.

Conclusion: Contextual threat does not enhance the attentional capture of pain-cues when they are presented concurrently with competing task demands. The study could, however, replicate a generally enhanced attentional processing of emotional cues in high pain vigilant subjects. This underpins that hypervigilance to pain is related to changes in emotional processing.

Keywords: vigilance to pain, primary task paradigm, PVAQ, pain face, threat

\section{Introduction}

Vigilance to pain is defined as an automatic and unintentional processing of painrelated stimuli at the cost of competing stimuli and is assumed to occur because of the outstanding salience of pain-related stimuli. ${ }^{1}$ A majority of the experimental tests for vigilance to pain apply symbols of pain, ie, words or pictures, and not "true" physical pain (for a review, see Crombez et $\mathrm{al}^{2}$ ). This can be especially sensible to detect painprone individuals because attentional capture by physical pain is a normal and adaptive function, while being already very vigilant to pain-signaling cues can be taken as an indicator of dysfunctional attentional disposition for pain experiences. ${ }^{3}$

For adequately operationalizing vigilance to pain, several experimental paradigms may be useful. One definite appropriate way is using the primary task paradigm, which let the attentional capture by the pain-signaling stimuli compete with more task-relevant stimuli. Only very salient pain-related stimuli can become the focus of 
attention under such conditions. Beside the dot-probe task, as the best known test for vigilance to pain, ${ }^{4-13}$ also paradigms that allow the assessment of event-related brain potentials (ERPs), enabling an easy differentiation between the various stages of information processing, can be run under such primary task conditions. ${ }^{14,15}$ In a recent ERP study with pain and emotional faces presented in a primary task paradigm, we found that subjects describing themselves as vigilant to pain by use of a questionnaire responded more strongly to the entire set of faces indicating a general hypervigilance to emotional, potentially threatening cues. ${ }^{16}$ This finding leads to the next question whether situational factors are of relevance beside the individual ones. Situational threat may qualify as such a factor. To the best of our knowledge, only the study of Boston and Sharpe ${ }^{17}$ assessed the effects of situational threat on the attentional processing of pain signals, finding attentional bias to affective pain words during threat induction. In anxiety research, such context effects have already been examined more broadly using a number of experimental approaches with varying results. ${ }^{18-22}$

In order to examine attentional processing of pain signals under conditions of situational threat, we used aversive electrical stimulation. A stimulus intensity just below the individual pain-threshold appeared to be most appropriate because it evokes an expectation of pain but not pain itself. We established three threat conditions: 1) control condition without stimulation, 2) "intermittent threat" condition with irregularly applied aversive stimulation, and 3) "continuous threat" condition with regularly applied aversive stimulation. Unpredictable electro-stimuli have been often used successfully in "threat of shock" procedures in order to induce anxiety whereas predictable shocks do rather trigger fear responses. ${ }^{23,24}$ We hypothesized that increases in situational threat lead to a prioritized attentional processing of pain-cues, which becomes especially manifest in individuals with high levels of vigilance to pain. As a secondary hypothesis, in the attempt to replicate the findings of Lautenbacher et al, ${ }^{16}$ we expected to find a general enhanced attentional processing of pain and emotional faces in hypervigilant subjects.

Six ERP components for assessing early (P100, P200, and early posterior negativity [EPN]) and late processing (P300, early and late late positive complex [LPC]) of task-irrelevant pain and other emotional facial cues were parameterized.

\section{Materials and methods Subjects}

A total of 132 healthy subjects, equally distributed in four age categories (18-29, 30-39, 40-49, and 50-65 years), were recruited via announcement in newspapers, public buildings in Bamberg, and among students of the University of Bamberg. We intended to recruit a broad age range and not to rely mainly on undergraduate students in order to achieve a high external validity of our results, ie, comparability with populations of chronic pain patients. Subjects had normal or corrected-to-normal eyesight. Preliminary to testing, all subjects were screened by trained psychologists using stringent and standardized exclusion criteria: history of any psychiatric (assessed with SCID-I, a structured clinical interview according to diagnostic and statistical manual of mental disorders-IV) ${ }^{25}$ or neurological disorders, substance abuse, psycho-pharmacological treatment, use of analgesics, acute or chronic pain, previous major surgical intervention, or prosopagnosia. A special focus of the interview was the pain history; it was addressed by asking the subjects separately for acute and chronic pain experiences (current and past pain) and by checking for potentially painful physical conditions (migraine, back pain, rheumatoid arthritis, etc). Based on the SCID, seven subjects were excluded from the study because of a potential psychiatric diagnosis. One further subject was excluded because of a potential pain syndrome. Due to artifacts in the electro-encephalogram (EEG) and high error rates in the behavioral data, 14 further subjects were excluded so that the sample was reduced to $\mathrm{N}=110$ for the final analyses. For the sample characteristics, see "Sample characteristics" section.

Subjects were asked to refrain from smoking for 1 hour prior to testing because nicotine could have an effect on attentional performance. Thirty-eight of the subjects had a university degree, 85 had a high school degree (29 subjects out of the 85 were students), and one was without formal school degree. Except for students who participated to fulfill course requirements, all subjects were paid $40 €$ for attendance. All gave informed consent and were free to terminate the experiment at any time. The study was approved by the Ethical Committee of the University of Bamberg.

\section{Design and procedure}

For examining the effects of context and individual predisposition on attentional capture by pain-cues, we applied a mixed design with two between-subject factors: 1) contextual threat and 2) self-reported vigilance to pain, and three factors with repeated measures (for the EEG data), and two factors with repeated measures (for the reaction time data).

For the between-subject factor "vigilance to pain" a median split according to scores of the Pain Vigilance and Awareness Questionnaire (PVAQ) (see "Self-reported 
vigilance to pain") was used. The three conditions of the factor "contextual threat" consisted of two experimental groups with aversive electro-stimulation and a control group without electro-stimulation (see "Threat manipulation (context)"). Subjects were selected and assigned to the three groups of the between-subject factor "contextual threat" so that sex and age were equally distributed. That means that except for the matching criteria "age" and "sex", subjects were randomly assigned.

The sessions took place between 9.00 am and $6.00 \mathrm{pm}$ and lasted for approximately 1.5 hours. On arrival at the laboratory, subjects were informed about the course and the duration of the experiment, asked to sign the informed-consent form, and to fill out the Vividness of Visual Imagining Questionnaire-Prosopagnosia regarding their ability to recognize and imagine faces. ${ }^{26}$ We included the Vividness of Visual Imagining Questionnaire-Prosopagnosia to allow for the exclusion of clinical states of prosopagnosia and to assess the degree of sub-clinical states of prosopagnosia.

Different kinds of electrodes for physiological recordings and electrical stimulation were attached. For the painthreshold assessment (see "Electro-stimulus characteristics") and electro-stimulation (see "Electro-stimulus characteristics"), stimulation electrodes were attached to the arm. Further, recording electrodes for the assessment of sympathetic skin response (SSR) (see "Sympathetic skin response") were fixed to the arm. Additionally, recording electrodes were attached to the scalp for EEG assessment (see "EEG recording").

First, individual pain-thresholds were assessed for the subjects in the two experimental threat conditions with electro-stimulation (see "Threat manipulation (context)"). Then, subjects were seated in front of a 20-inch computer screen ( $1 \mathrm{~m}$ viewing distance), on which the experimental task was presented. The experimenter gave instructions verbally and left the room before the start of testing. Subjects were observed through a monitoring camera. If further interaction between experimenter and subject was needed during the test, then it was done through a two-way intercommunication system. The experimental task (see "Visual discrimination task") was started thereafter. After completion, subjects were cleared of all electrodes, and were asked to complete the PVAQ (see "Self-reported vigilance to pain"). At the end subjects were debriefed.

\section{Experimental paradigm and material} Visual discrimination task

In all, 96 black and white pictures of faces from four emotional categories (anger, happy, neutral, and pain; 24 pictures for each category), of which $50 \%$ were overlaid with a semi-transparent grid (12 with and 12 without grid in each emotional category), were presented in a randomized order. The stimulus material was identical to our previous study. ${ }^{16}$ The stimuli were originated from the Montréal Pain and Affective Face Clips, which is a collection of 1-secondvideos of eight professional actors (four females), mimicking affective and painful facial expressions. ${ }^{27}$ Extraction of the monochrome still images and their validation is described in Baum et al. ${ }^{28}$

We presented the pictures in a primary task paradigm, requiring a visual discrimination of the presence or absence of the grid without any task relevance of the emotional content of the faces. No particular instructions were given regarding the pictures' content; instead, subjects were instructed to indicate in each trial whether a picture with or without a grid was presented by pressing one of two response buttons as fast as possible. Reaction times and errors were recorded.

Each single trial started with the question "Gitter?" (English: grid) presented for $700 \mathrm{~ms}$, reminding the subject of the upcoming task (ie, to decide whether the presented picture was overlaid with a grid) (Figure 1). In the two conditions with contextual threat, electro-stimuli were presented at the very beginning of the trials (ie, at $t=0$, simultaneous to the onset of the presentation of the question "Gitter?"). In the control condition, no electrostimulation was applied. Then, the picture of emotional or neutral faces (with or without a grid) was presented for $300 \mathrm{~ms}$ and subjects had to press either the "grid" or the "no grid" button. Immediately following the response,

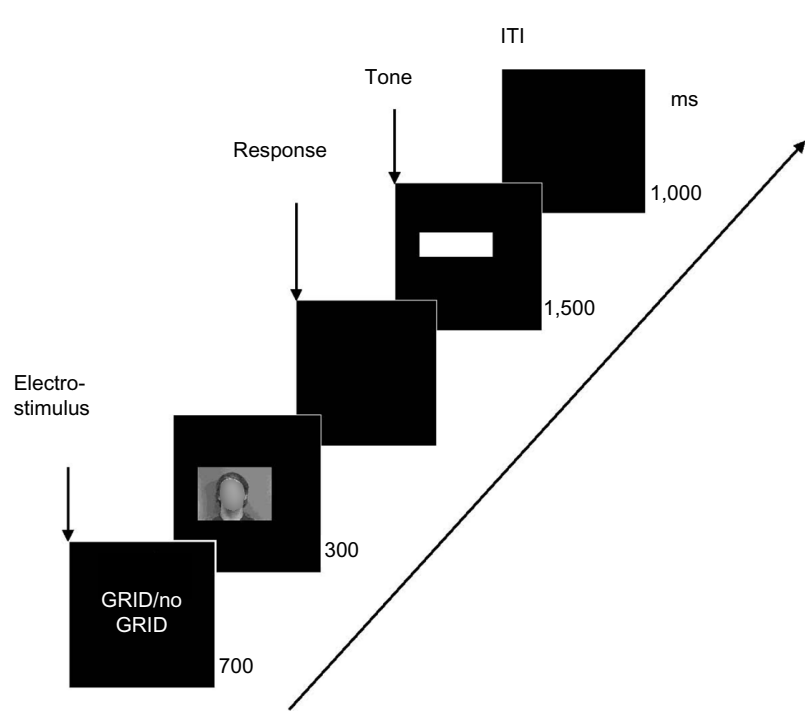

Figure I Sequence of experimental stimuli (trial format). Abbreviation: ITI, intertrial interval. 
a white bar was presented on the screen concurrently with a tone of $1,000 \mathrm{~Hz}$ for $1,500 \mathrm{~ms}$. Subjects were instructed to use this interval for eye blinks and to abstain from blinking for the rest of the trial; this provision was taken to minimize eye blinks during the relevant periods of data acquisition. The trial sequence ended with a black screen for 1,000 ms serving as inter-trial interval (Figure 1). Subjects were familiarized with the procedure by running 10 training trials.

The primary task was designed to be of medium difficulty and had been applied in a previous study of our group. ${ }^{16}$ The mean error rate in the present study was 3.6 (standard deviation $[\mathrm{SD}]=11.5$; range: $0-81$ ). Looking at the error distribution, we found that four subjects had an error rate of 33 or above. Such a high error rate may indicate that the instructions were not understood correctly or were deliberately not followed. Hence, we decided to exclude subjects with an error rate of 2.5 SD above the sample mean. The error distribution of the remaining sample showed that the primary task was of low to medium difficulty; nearly half of the subjects $(44.2 \%)$ were without any error, again about half of the subjects $(52.5 \%)$ produced $1-7$ errors in 96 trials and only a few subjects $(3.3 \%)$ produced larger numbers of errors (9 or more).

\section{Threat manipulation (context)}

\section{Types of contextual threat conditions}

As mentioned above, our study included two experimental conditions with threatening context and a control condition without threat. Threat was induced by electrical stimulation at the beginning of a trial.

In one of the threat conditions 24 electro-stimuli were applied in one-fourth of the experimental trials with a nonregular frequency (intermittent threat condition). The entire 96 trials were divided into 12 blocks of 8 trials each. In each block, two electrical stimuli were applied, one of them was always presented with the last trial of a block and the second one was presented with equal likelihood of appearance in any of the other trials within that block. Each block ended with a visual analog scale (VAS) rating of the electrical stimuli (see "VAS rating").

In the other experimental threat condition, 96 electro-stimuli were applied at the beginning of each single experimental trial in a regular frequency (continuous threat condition); this corresponded to a likelihood of $100 \%$ appearance of electrostimulation. VAS ratings of stimulation intensity were again taken after each eighth trial.

\section{Electro-stimulus characteristics}

For intermittent and continuous threat conditions, individual pain-thresholds were assessed in order to tailor threat intensity of electro-stimulation to the individual pain sensitivity. The assessment protocol of pain-thresholds was the same as described by Lautenbacher et al. ${ }^{29}$

Before testing, all subjects were trained until they understood all of the procedures and were able to follow the instructions. Starting at the individual level of the detectionthreshold, five ascending series were run in steps of $0.1 \mathrm{~mA}$, until the subject signaled the first sensation of pain (single ascending staircase method). An upper limit was set at $7.5 \mathrm{~mA}$ for safety reasons. The pain-threshold was calculated as the mean amperage of the last four trials.

Electrical stimuli were delivered by a constant-current stimulator (Pulsar 6i) and consisted of 15 4-ms monophasic rectangular pulses with a stimulus onset asynchrony of $10 \mathrm{~ms}(100 \mathrm{~Hz})$. These parameters resulted in duration of $144 \mathrm{~ms}$ per stimulus train. After the skin was cleaned and abraded, two mono-polar surface electrodes with a surface area of $0.3 \mathrm{~cm}^{2}$ were attached with a distance of $3 \mathrm{~cm}$ from each other in the center of the volar distal forearm of the non-dominant hand.

For stimulation in the two experimental threat conditions, the intensity of electro-stimuli was set to $80 \%$ of the individual pain-threshold because the stimulation was intended to be already aversive but still not painful. Although pain-stimuli may be considered as the most aversive cues, we decided to use stimuli below pain-threshold for establishing a threat context without pain, which may have been a too potent distractor. More importantly, the presentation of painful electro-stimuli might have fully activated the pain matrix, and thereby masked any brain activity due to the attentional processing of pain-related cues, ie, facial expressions of pain.

\section{Manipulation check \\ Sympathetic skin response}

SSR was assessed by an electro-diagnostic device of Suess Medizintechnik (SUEmpathy100). A sampling rate of $512 \mathrm{~Hz}$ was used. For recording, two differential surface electrodes were used, one fixed to the palm of the non-dominant hand and the other fixed to the proximal third of the forearm of the same body side. The reference electrode was also attached to the proximal third of the forearm of the same body side.

SSR was assessed, commencing with the trial concurrently with onset of the question "Gitter?", while in the intermittent 
and continuous threat conditions the electro-stimulus was started. The SSR signal of every eighth trial was entered into further analysis, resulting into 12 SSRs to be considered. In the threat conditions, these SSRs were always preceded by an electrical stimulus.

Amplitude and latency of the SSR were measured. Amplitude was defined as voltage difference between the initial negative and the positive peak of the biphasic response. Latency was defined as time from trial onset to the onset of the negative deflection. Responses beginning with a positive deflection or latency under $600 \mathrm{~ms}$ were excluded from further analysis.

For statistical analyses, the mean values of amplitudes were used. The SSR amplitudes were log transformed $(\log [\mathrm{SSR}+1])^{30}$ to normalize the distribution of responses. Missing values in the SSRs were padded with zeros.

\section{VAS rating}

Additionally, subjects in the intermittent and continuous threat conditions were asked to rate the electro-stimuli of every eighth trial on VAS (100 mm long) indicating "threat" (from not threatening to extremely threatening) and "unpleasantness" (from very pleasant to very unpleasant). This VAS rating was done by moving a cursor that was driven by the two response buttons also used for recording reaction times (see "Reaction time"). The initial position of the cursor was always randomized. The ratings could take on a value between 0 and 100. In total, 12 ratings of "threat" and "unpleasantness" had to be given each in the two threat conditions, which were averaged to obtain a mean score for "threat" and for "unpleasantness".

\section{Self-reported vigilance to pain}

Subjects were asked to self-report their vigilance to pain by filling out the German version of the PVAQ, ${ }^{31}$ which was developed as a comprehensive measure of attention to pain and has been validated for the use in chronic pain and nonclinical samples. It consists of 16 items that are rated on a six-point scale assessing awareness, vigilance, preoccupation, and observation of pain. The median in the present sample was 32.5, which allowed grouping of the subjects in those being high and low in pain vigilance as between-subject factor.

\section{Behavioral and EEG measures Reaction time}

As stated in the "Visual discrimination task" section, subjects were instructed to indicate in each trial whether a picture with or without a "grid" was presented by using two response buttons of a response box (for a more detailed description of the reaction time measurement, see Baum et $\mathrm{al}^{13}$ and Lautenbacher et $\mathrm{al}^{16}$ ). Reaction time in $\mathrm{ms}$ and number of errors were taken as measures.

\section{EEG recording}

EEG was recorded from five sites (frontal at $\mathrm{Fz}$; central at $\mathrm{Cz}$; parietal at $\mathrm{Pz}$; and occipital at $\mathrm{O} 1$ and $\mathrm{O} 2$ ) and $\mathrm{A} 1 / \mathrm{A} 2$ (mastoid) with a commercially available electrode cap (ElectroCap International, Inc., Eaton, OH, USA) with tin electrodes placed according to the international 10-20 system. ${ }^{32}$ For measuring the vertical electro-oculogram (EOG) two tin electrodes were placed above and below the right eye; for measuring horizontal EOG, two further tin electrodes were placed at the outer canti. The EEG, including vertical and horizontal EOG, was continuously recorded with a DC Brain Amp amplifier (Brain Products GmbH, Gilging, Germany) with a sampling rate of $1,000 \mathrm{~Hz}$, a notch-filter at $50 \mathrm{~Hz}$, and a low pass filter at $70 \mathrm{~Hz}$. Off-line, data were again processed with $30 \mathrm{~Hz}$ low pass and $0.1 \mathrm{~Hz}$ high pass filters. All channels were primarily recorded with a $\mathrm{Cz}$ reference. Off-line, data were re-referenced to linked mastoids (A1 and A2), whereby $\mathrm{Cz}$ was regained for further analysis. Sweeps of 1,000 ms duration starting $200 \mathrm{~ms}$ before stimulus onset (pictures with facial expression of pain, anger, joy or a neutral expression) were extracted and adjusted to the $50 \mathrm{~ms}$ baseline period just before stimulus onset. Further, data were corrected for EOG artifacts using a regression method..$^{33}$ Elimination of sweeps with artifacts was done by automatically detecting sweeps with amplitudes outside a range of $\pm 80 \mu \mathrm{V}$ and with gradients over $100 \mu \mathrm{V}$ voltage change/sampling point. ${ }^{20,34-36}$ Further, single trials were visually inspected to exclude sweeps with uncorrected eye blinks, dominant alpha waves, and generally distorted sweeps due to high-frequency noise. Averaged ERPs assessed at the five electrode locations (Fz, Cz, Pz, O1, and $\mathrm{O} 2$ ) for the four emotional categories (pain, anger, happy, and neutral) in both the "grid" or "no grid" conditions were calculated. Averages were only calculated if at least eight out of twelve sweeps per condition were accepted in the artifact rejection procedure. If in one or more experimental conditions no averages could be calculated, then the subject affected was excluded. The described rigorous procedure of artifact rejection forced us to exclude ten subjects.

Altogether, parameters for six ERP components were calculated. EPN was calculated as mean amplitudes at $\mathrm{O} 1$ and $\mathrm{O} 2$ in a time window of $240-280 \mathrm{~ms}$ after stimulus 
onset. For EPN, a relative decrease of brain activity elicited by emotional compared with neutral stimuli was reported. ${ }^{36,37}$

For the LPC, we distinguished - according to the literature $^{38-41}$ and guided by visual inspection of the grand averages - between an early activation at 260-460 ms (early LPC) and a late activation at 460-800 ms (late LPC). These potentials are measured as mean amplitudes because no clear peak could often be discerned in this time range. While EPN is most prominent at temporo-occipital locations, LPC activations were best recorded at midline electrodes. ${ }^{36,42,43}$

In addition, we extracted positive peaks in a time range from 260 to $400 \mathrm{~ms}$ after stimulus onset (P300) at midline electrodes, which has also been previously reported from similar studies. ${ }^{14,15}$ Further, we extracted averaged peak amplitudes of an earlier positive deflection in the time range of 170-230 ms after stimulus onset (P200) at midline electrodes, which has been observed as being modulated by emotional/ pain-related contents in passive viewing paradigms without task requirements. ${ }^{44,45}$ Further, P100 was exported as peaks at $\mathrm{O} 1$ and $\mathrm{O} 2$ in a time window of 90-150 ms after stimulus onset. ${ }^{20,37,34,46-48}$ This component reflects early visual processing and is therefore most prominent in occipital regions.

\section{Statistics}

\section{Behavioral and EEG data}

For evaluation of the reaction times, we calculated a mixed design analysis of variance (ANOVA) with the within-subject factors, EMOTION (anger, happy, neutral, and pain faces), and GRID (grid and no grid), and the between-subject factors, CONTEXT (continuous and intermittent threat and control condition), and VIGILANCE (high and low pain vigilant [HPV and LPV] subjects).

For the averaged ERPs of the components P100, P200, EPN, P300, early LPC, and late LPC, we calculated mixed design ANOVAs with the within-subject factors, EMOTION (anger, happy, neutral, and pain faces), GRID (grid and no grid), ELECTRODE (Fz/frontal, Cz/central, and Pz/parietal for P200, P300, early and late LPC; O1 and O2 for P100, and EPN), and the between-subject factors, CONTEXT (continuous and intermittent threat and control condition), and VIGILANCE (HPV and LPV subjects). Only main and interaction effects relating to our hypotheses were subjected to fine-grain post hoc analyses.

Guided by our hypothesis we looked for main and interaction effects including the factor, EMOTION, with a focus on the three-way interactions of EMOTION with CONTEXT and VIGILANCE. Further, we looked for interaction effects of EMOTION with VIGILANCE and EMOTION with CONTEXT in order to see whether pain-cues are prioritized in attentional processing as a function of individual predisposition or as a function of contextual threat. In order to replicate the previously reported general hypervigilance in HPV subjects, we scrutinized the interaction effect between VIGILANCE and CONTEXT.

For post hoc tests, we used analyses of variance and $t$-tests for dependent samples for specifying effects of the factor EMOTION (eg, comparing anger vs happy, anger vs neutral, anger vs pain, happy vs neutral, happy vs pain, neutral vs pain).

\section{Manipulation check}

For the manipulation check on the basis of the SSRs, we calculated a one-way independent ANOVA with the three groups (intermittent and continuous threat and control condition). If a significant effect was found, then we used $t$-tests as post hoc tests for independent samples comparing the three different threat categories of this factor with each other (ie, continuous vs intermittent; continuous vs control; intermittent vs control). For the manipulation check on the basis of the VAS ratings, we calculated $t$-tests for independent samples to compare VAS ratings of "unpleasantness" between the group with intermittent and continuous threat stimulation, and "threat" also between the group with intermittent and continuous threat stimulation. If violation of sphericity occurred in any of the ANOVAs, then we used the Greenhouse-Geisser correction. We set $\alpha$ to $\leq 0.05$ throughout.

\section{Results \\ Sample characteristics}

The sample used for further analyses $(\mathrm{N}=110)$ consisted of 58 men and 52 women with a mean age of 39.5 years ( $\mathrm{SD}=12.6$ years; range: $19-64$ years). The control group contained $14 \mathrm{HPV}$ and $21 \mathrm{LPV}$ subjects, the group in the condition with intermittent threat stimulation 18 HPV and 19 LPV subjects and the group in the condition with continuous threat stimulation $23 \mathrm{HPV}$ and $15 \mathrm{LPV}$ subjects. Of the female subjects, about $40 \%$ used contraceptives, $17 \%$ were in the first third of their menstrual cycle (day 1-8 after cycle-onset according to self-report), $10 \%$ were in the second third (day 9-17), 14\% were in the third third (after day 17), and 19\% were post-menopausal.

\section{Manipulation check}

For the manipulation check on basis of the SSRs, the three context conditions (control condition, continuous, and 
intermittent threat stimulation) were compared. The VAS ratings (dimensions "threat" and "unpleasantness") were only compared between the two conditions with threat stimulation.

\section{Sympathetic skin response}

For the SSR amplitudes, a significant main effect was found $(F[2 ; 107]=6.57 ; P=0.002)$. The condition with intermittent threat stimulation had the highest amplitudes $($ mean $(M)=3.15$; $\mathrm{SD}=1.80$; range: $0.00-6.24$ ), followed by the condition with continuous threat stimulation $(\mathrm{M}=2.10 ; \mathrm{SD}=1.68$; range: $0.00-5.08)$ and the control condition with the lowest amplitudes ( $\mathrm{M}=1.69 ; \mathrm{SD}=1.88$; range: $0.00-5.66$ ). Post hoc $t$-tests for independent samples revealed significant differences between the "intermittent threat" condition and the control condition $(t[71]=3.40 ; P=0.001)$, and between the "intermittent threat" condition and the "continuous threat" condition $(t[73]=2.61 ; P=0.011)$. The differences between the "continuous threat" condition and the control condition did not reach a level of significance $(P$-value $>0.05)$.

\section{VAS rating}

VAS ratings of "unpleasantness" and "threat" of the electrical threat-stimuli could only be recorded in the two threat stimulation conditions but not in the control condition.

Regarding the dimension "unpleasantness" slightly higher ratings were found in the "intermittent threat" condition ( $\mathrm{M}=37.4 ; \mathrm{SD}=22.9$; range: 1.1-93.0) compared with the "continuous threat" condition $(\mathrm{M}=32.3$; $\mathrm{SD}=18.7$; range: $0.0-60.3)$. Yet, this difference was not significant $(P$-value $>0.05)$. Also regarding the dimension "threat" higher ratings were found for the "intermittent threat" condition ( $\mathrm{M}=25.8 ; \mathrm{SD}=21.8$; range: 0.0-92.7) compared with the "continuous threat" condition $(\mathrm{M}=16.6 ; \mathrm{SD}=18.4$; range: $0.0-60.8)$. Yet, this difference was not significant $(P$-value $>0.05)$.

\section{Summary}

Based on the SSR amplitudes, our context manipulation can be regarded as successful. The data indicate that the intermittent and unpredictable electrical threat stimulation compared with the continuous and predictable threat stimulation and the control condition induced a higher state of sympathetic arousal. However, regarding the subjective experience of "threat" and "unpleasantness", the two threat conditions did not differ from each other.

\section{Behavioral data - reaction times}

Descriptive statistics (M and SD) are shown in Table 1. The reaction times were $461.8 \mathrm{~ms}$ ( $\mathrm{SD}=77.3$; range: $257.6-720.3$ ) on average. ANOVA revealed a main effect for the factor GRID $(F[1 ; 106]=123.99 ; P<0.001)$, with reaction times being significantly prolonged in the "no grid" condition. Also, a significant main effect for EMOTION $(F[3 ; 318]=5.40 ; P=0.001)$ as well as a significant interaction of EMOTION $\times$ GRID $(F[3 ; 318]=3.87 ; P=0.010)$ were revealed. For explaining the interaction effect EMOTION $\times$ GRID, post hoc analyses of variance were computed and revealed a significant main effect for EMOTION for both in the "grid" condition $(F[3 ; 327]=4.51 ; P=0.004)$ and in the "no grid" condition $(F[3 ; 327]=4.63 ; P=0.003)$. Results of post hoc $t$-tests for dependent samples are shown in Table 2. In the "grid" condition, anger faces had longer reaction times than neutral and happy faces; in the "no grid" condition, happy faces had shorter reaction times than the three other face categories.

Furthermore, for the between-subject factor CONTEXT, we found a significant main effect $(F[2 ; 106]=3.10 ; P=0.049)$ (descriptive statistics are shown in Table 1). Post hoc $t$-tests for independent samples revealed significant longer reaction times for the "intermittent threat" condition compared with the "continuous threat" condition $(t[73]=2.94 ; P=0.004)$. The between-subject factor VIGILANCE produced no significant

Table I Descriptive statistics of reaction times (in $\mathrm{ms}$ ) in the primary task paradigm for the four emotional categories (facial expressions of anger, pain, and joy as well as neutral faces) in the "grid" and the "no grid" conditions, and for the three conditions of contextual threat manipulation (control condition, continuous, and intermittent threat)

\begin{tabular}{|c|c|c|c|c|c|}
\hline & Overall & Anger & Happy & Neutral & Pain \\
\hline & Mean (SD) & $\overline{M e a n}(\mathrm{SD})$ & $\overline{M e a n}(\mathrm{SD})$ & $\overline{M e a n}(\mathrm{SD})$ & Mean (SD) \\
\hline Overall & $46 I .8(77.3)$ & $464.9(78.5)$ & $457.0(77.4)$ & $462.4(80.4)$ & $462.8(77.3)$ \\
\hline "Grid" & $446.8(73.8)$ & $452.1(74.5)$ & $444.0(74.8)$ & $443.1(80.2)$ & $448.0(73.7)$ \\
\hline "No grid" & $476.8(83.2)$ & $477.7(87.0)$ & $470.0(84.8)$ & $48 I .7$ (85.5) & $477.6(85.3)$ \\
\hline Control condition & $462.4(91.5)$ & $465.2(92.1)$ & 455.9 (89.5) & $463.3(95.2)$ & 465.I (92.4) \\
\hline "Continuous threat" & $438.5(60.0)$ & $440.7(61.8)$ & $436.3(62.4)$ & $437.6(63.2)$ & $439.4(59.2)$ \\
\hline "Intermittent threat" & $483.9(73.2)$ & $488.2(74.2)$ & $478.3(74.9)$ & $485.8(75.2)$ & $483.4(73.2)$ \\
\hline
\end{tabular}

Abbreviation: SD, standard deviation. 
Table 2 Results of post hoc $t$-tests for dependent samples ( $t$-values, $P$-values) for the differences between the four categories of emotional face expression (anger, pain, joy, and neutral) as regards the reaction times (separate for the "grid" and "no grid" conditions), PI00 (only for the "grid" condition in LPV subjects), P300 (only for the "grid" condition), early LPC (only for the "grid" condition), and late LPC (only for the "continuous threat" condition); significant findings are marked in bold

\begin{tabular}{|c|c|c|c|c|c|c|}
\hline & \multicolumn{2}{|l|}{ Reaction times } & \multirow{2}{*}{$\begin{array}{l}\text { PI00 } \\
\text { "Grid" condition } \\
\text { in LPV subjects }\end{array}$} & \multirow{2}{*}{$\begin{array}{l}\text { P300 } \\
\text { "Grid" } \\
\text { condition }\end{array}$} & \multirow{2}{*}{$\begin{array}{l}\text { Early LPC } \\
\text { "Grid" } \\
\text { condition }\end{array}$} & \multirow{2}{*}{$\begin{array}{l}\text { Late LPC } \\
\text { "Continuous threat" } \\
\text { condition }\end{array}$} \\
\hline & $\begin{array}{l}\text { "Grid" } \\
\text { condition }\end{array}$ & $\begin{array}{l}\text { "No grid" } \\
\text { condition }\end{array}$ & & & & \\
\hline Anger vs happy & $t=2.83 ; \boldsymbol{P}=\mathbf{0 . 0 0 6}$ & $t=2.69 ; P=0.008$ & $t=-1.82 ; P=0.075$ & $t=-0.34 ; P=0.732$ & $t=-0.26 ; P=0.797$ & $t=2.83 ; P=0.007$ \\
\hline Anger vs neutral & $t=3.33 ; P=0.00 \mathrm{I}$ & $t=-1.20 ; P=0.233$ & $t=-3.78 ; P<<0.00 I$ & $t=-2.76 ; P=0.007$ & $t=-2.34 ; P=0.02 I$ & $t=2.79 ; P=0.008$ \\
\hline Anger vs pain & $t=I .44 ; P=0.153$ & $t=0.03 ; P=0.973$ & $t=-1.54 ; P=0.130$ & $t=-2.31 ; P=0.023$ & $t=-1.83 ; P=0.069$ & $t=I .4 I ; P=0.167$ \\
\hline Happy vs neutral & $t=0.36 ; P=0.721$ & $t=-3.90 ; \boldsymbol{P}<\mathbf{0 . 0 0 1}$ & $t=-2.67 ; P=0.010$ & $t=-2.44 ; P=0.016$ & $t=-2.00 ; P=0.048$ & $t=-0.39 ; P=0.697$ \\
\hline Happy vs pain & $t=-1.44 ; P=0.154$ & $t=-2.36 ; P=0.020$ & $t=-0.28 ; P=0.779$ & $t=-1.74 ; P=0.085$ & $t=-1.57 ; P=0.120$ & $t=-1.58 ; P=0.123$ \\
\hline Neutral vs pain & $t=-1.78 ; P=0.77$ & $t=1.20 ; P=0.233$ & $t=2.42 ; P=0.019$ & $t=0.76 ; P=0.446$ & $t=0.47 ; P=0.637$ & $t=-0.95 ; P=0.349$ \\
\hline
\end{tabular}

Notes: Post hoc $t$-tests for the differences between the categories of emotional face expressions were only computed and subsequently reported in this table if prior analyses of variance revealed a significant effect for the factor "emotion" (for details on the performed analyses of variance see the text).

Abbreviations: LPC, late positive complex; LPV, low pain vigilant.

main effect $(F[1 ; 106]=1.32 ; P=0.254)$ or interaction effects (all $P$-values $>0.05$ ).

Summing up, reaction times were affected by the two task conditions of the GRID factor indicating that the presence or absence of the primary task stimulus impacted on task performance. Self-reported vigilance to pain did not affect the reaction times. The "intermittent threat" condition produced a slowing of reaction times when compared with the "continuous threat" condition.

\section{EEG data}

Descriptive statistics (M and SD) for the four categories of facial expressions are listed for each of the ERP components in Table 3. All within-subject main effects and interactions as well as main effects for the between-subject factor CONTEXT and the interactions between CONTEXT and EMOTION for the different ERP components are shown in Table 4. All main effects for the between-subject factor VIGILANCE and the significant interaction effects including this factor are listed in a separate table (Table 5) because our main as well as our secondary hypothesis relate to this factor.

\section{PI00}

There were significant main effects for the factors GRID, ELECTRODE, and EMOTION (Table 4), as well as a significant interaction effect between GRID, EMOTION, and VIGILANCE (Table 5). This interaction was further analyzed with post hoc tests and can be explained by a significant "emotion" effect for LPV subjects in the "grid" condition (Tables 2 and 5). Anger ( $\mathrm{M}=6.20 \mu \mathrm{V} ; \mathrm{SD}=3.81$; range: $0.20-17.58)$, happy ( $\mathrm{M}=6.70 \mu \mathrm{V} ; \mathrm{SD}=3.36$; range: -0.47 to 16.27 ), and pain faces $(\mathrm{M}=6.79 \mu \mathrm{V} ; \mathrm{SD}=3.19$; range: $0.26-14.88)$ had significantly lower $\mathrm{P} 100$ potentials in the "grid" condition in LPV subjects than neutral faces $(\mathrm{M}=7.48 \mu \mathrm{V} ; \mathrm{SD}=3.65$; range: -0.10 to 15.90$)$.

\section{Early posterior negativity}

There was a significant main effect for the factor GRID (Table 4). A significant main effect for the between-subject

Table 3 Mean and SD $(\mu \mathrm{V})$ of the different ERP components (averaged across frontal, central, and parietal midline sites for P200, P300, early LPC, late LPC, and across the two occipital sites for PI00, EPN) for the four categories of emotional face expression; for P300 and early LPC values are also given for the "grid"/"no grid" conditions separately, for late LPC values are also given separately for the three threat conditions (control condition, continuous, or intermittent threat)

\begin{tabular}{|c|c|c|c|c|}
\hline & $\begin{array}{l}\frac{\text { Anger }}{\text { Mean }} \\
(\mathrm{SD})\end{array}$ & $\begin{array}{l}\text { Happy } \\
\text { Mean } \\
\text { (SD) }\end{array}$ & $\begin{array}{l}\frac{\text { Neutral }}{\text { Mean }} \\
\text { (SD) }\end{array}$ & $\begin{array}{l}\frac{\text { Pain }}{\text { Mean }} \\
\text { (SD) }\end{array}$ \\
\hline PI00 & $6.58(3.36)$ & $7.10(3.71)$ & 7.14 (3.62) & $7.12(3.61)$ \\
\hline EPN & $3.33(3.21)$ & 3.59 (3.45) & $3.63(3.56)$ & $3.76(3.7 I)$ \\
\hline P200 & $5.76(2.33)$ & $5.97(2.29)$ & $6.11(2.35)$ & $6.02(2.26)$ \\
\hline P300 overall & $4.80(2.7 I)$ & $5.05(2.72)$ & $5.15(2.67)$ & $5.15(2.70)$ \\
\hline P300 “no grid” & 4.57 (3.02) & $5.00(3.02)$ & $4.62(2.80)$ & $4.78(2.75)$ \\
\hline P300 “grid" & $5.02(2.92)$ & $5.11(3.05)$ & $5.69(3.14)$ & $5.51(3.12)$ \\
\hline $\begin{array}{l}\text { Early LPC } \\
\text { overall }\end{array}$ & $2.03(2.27)$ & $.22(2.28)$ & $2.22(2.11)$ & $2.30(2.29)$ \\
\hline $\begin{array}{l}\text { Early LPC } \\
\text { "no grid" }\end{array}$ & $\mathrm{I} .87(2.55)$ & $2.19(2.50)$ & $1.79(2.15)$ & $2.04(2.33)$ \\
\hline $\begin{array}{l}\text { Early LPC } \\
\text { "grid" }\end{array}$ & $2.19(2.50)$ & $2.45(2.64)$ & $2.66(2.54)$ & $2.58(2.64)$ \\
\hline $\begin{array}{l}\text { Late LPC } \\
\text { overall }\end{array}$ & 8) & 78) & $57(1.72)$ & 2.62 (I.7I) \\
\hline $\begin{array}{l}\text { Late LPC } \\
\text { controls }\end{array}$ & $2.49(2.15)$ & $2.96(2.06)$ & 2.54 (1.91) & $2.66(1.91)$ \\
\hline $\begin{array}{l}\text { Late LPC } \\
\text { "continuous" }\end{array}$ & $3.02(1.46)$ & $2.38(1.65)$ & 2.47 (I.46) & $2.69(1.64)$ \\
\hline $\begin{array}{l}\text { Late LPC } \\
\text { “intermittent" }\end{array}$ & $2.35(1.65)$ & $2.75(1.61)$ & $2.7 \mathrm{I}(\mathrm{I} .8 \mathrm{I})$ & $2.53(1.62)$ \\
\hline
\end{tabular}

Abbreviations: EPN, early posterior negativity; ERP, event-related brain potential; LPC, late positive complex; SD, standard deviation. 


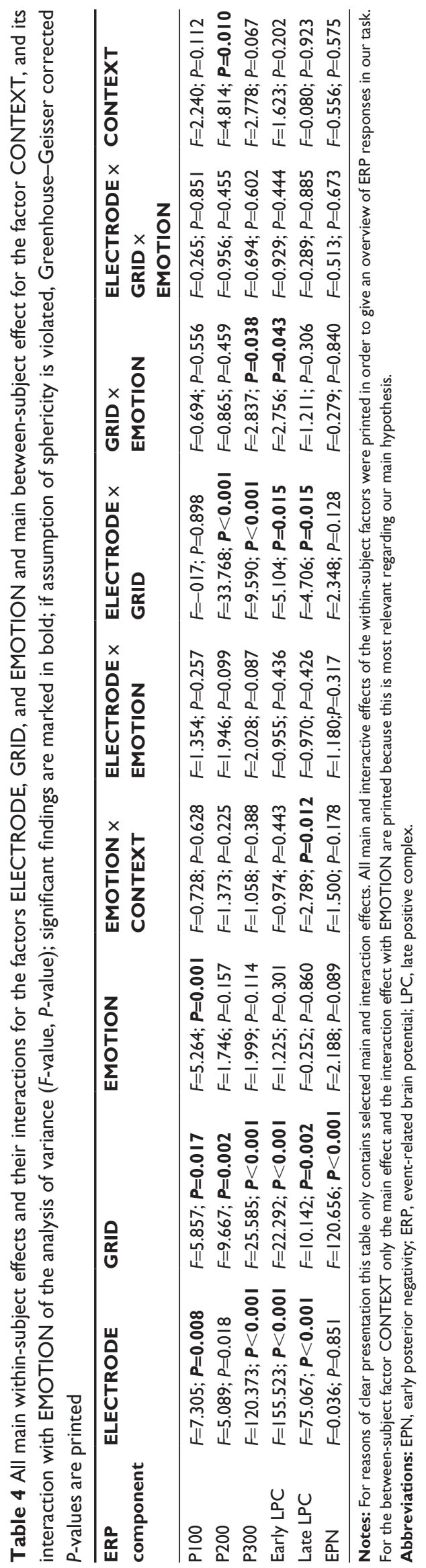

factor VIGILANCE as well as a significant interaction effect between the two between-subject factors VIGILANCE and CONTEXT were also found (Table 5). Post hoc analyses of variance revealed a significant effect for the factor VIGILANCE in the control condition $(F[1 ; 33]=5.610$; $P=0.024)$ with lower potentials, ie, enhanced negativity, for HPV subjects $(\mathrm{M}=1.70 \mu \mathrm{V}$; $\mathrm{SD}=4.25$; range: -4.55 to 10.18) compared with LPV subjects $(\mathrm{M}=4.70 \mu \mathrm{V} ; \mathrm{SD}=3.25$; range: 0.76-10.96) (Figures 2 and 3). In the "continuous threat" condition, potentials of HPV subjects ( $\mathrm{M}=3.03 \mu \mathrm{V}$; $\mathrm{SD}=2.57$; range: -1.34 to 8.32 ) were lower compared with LPV subjects $(\mathrm{M}=4.78 \mu \mathrm{V} ; \mathrm{SD}=3.55$; range: -2.11 to 12.32$)$. In the "intermittent threat" condition, potentials of LPV subjects $(\mathrm{M}=2.81 \mu \mathrm{V} ; \mathrm{SD}=2.25$; range: -1.05 to 7.92$)$ were lower compared with HPV subjects $(\mathrm{M}=3.63 \mu \mathrm{V} ; \mathrm{SD}=3.35$; range: -1.85 to 9.13 ). However, these differences between LPV and HPV subjects in the conditions with intermittent and continuous threat stimulation were non-significant (both $P$-values $>0.05$ ).

\section{P200}

There was a significant main effect for the factor GRID and a significant interaction effect between the factors GRID and ELECTRODE. Furthermore, a significant main effect for the between-subject factor CONTEXT was found (Table 4), which was due to higher potentials for the "continuous threat" condition ( $\mathrm{M}=6.63 \mu \mathrm{V} ; \mathrm{SD}=1.95$; range: 3.39-12.78) compared with the control condition $(\mathrm{M}=5.15 \mu \mathrm{V} ; \mathrm{SD}=1.53$; range: $1.80-8.66)(t[70]=3.56$; $P=0.001)$.

\section{P300}

There were significant main effects for the factors GRID and ELECTRODE as well as a significant interaction between the two factors (Table 4). Also, there were significant interaction effects of GRID with EMOTION (Table 4), and of GRID, ELECTRODE with VIGILANCE (Table 5). The interaction between GRID and EMOTION was further analyzed with post hoc testing. Post hoc analyses of variance computed separately for the two categories of the factor GRID revealed a significant main effect for EMOTION only in the "grid" condition $(F[3 ; 327]=3.713 ; P=0.012)$ but not in the "no grid" condition $(F[3 ; 327]=1.449 ; P=0.228)$. In the "grid" condition, anger and happy faces had lower potentials than neutral faces, and anger faces had also lower potentials than pain faces (see Table 3 for descriptive data; see Table 2 for results of post hoc $t$-tests for dependent samples). 
Table 5 All main and significant interaction effects including the between-subject factor VIGILANCE as well as the results of post hoc testing for significant effects including this factor for six ERP components

\begin{tabular}{|c|c|c|c|}
\hline ERP component & $\begin{array}{l}\text { VIGILANCE: } \\
\text { main effect }\end{array}$ & $\begin{array}{l}\text { VIGILANCE: significant } \\
\text { interaction effects }\end{array}$ & $\begin{array}{l}\text { Results of post hoc tests for } \\
\text { significant interaction effects } \\
\text { including the factor VIGILANCE }\end{array}$ \\
\hline PI00 & $F(I ; \mid 104)=0.039 ; P=0.845$ & $\begin{array}{l}\text { VIGILANCE } \times \text { EMOTION } \times \\
\text { GRID: } F(3 ; 3 \text { I } 2)=2.904 ; P=0.035\end{array}$ & $\begin{array}{l}\text { For "grid" trials in LPV subjects: all emotion } \\
\text { categories lower potentials compared to } \\
\text { neutral (all } P \text {-values }<0.05 \text { ) }\end{array}$ \\
\hline EPN & $F(I ; \mid 104)=4.329 ; P=0.040$ & $\begin{array}{l}\text { VIGILANCE } \times \text { CONTEXT: } \\
F(2 ; 104)=3.16 ; P=0.046\end{array}$ & $\begin{array}{l}\text { In the control condition lower potentials } \\
\text { for HPV vs LPV subjects }(P=0.024)\end{array}$ \\
\hline P200 & $F(I ; 104)=1.944 ; P=0.166$ & all $F$ 's $<1$ & - \\
\hline P300 & $F(I ; 104)=0.108 ; P=0.743$ & $\begin{array}{l}\text { VIGILANCE } \times \text { ELECTRODE } \times \\
\text { GRID: } F(2 ; 208)=3.397 ; P=0.046\end{array}$ & $\begin{array}{l}\text { For LPV subjects at Pz and Cz: higher } \\
\text { potentials in "grid" compared with "no } \\
\text { grid" trials (both } P \text {-values }<0.0 \text { I) }\end{array}$ \\
\hline \multirow[t]{3}{*}{ Early LPC } & $F(I ; \mid 104)=0.932 ; P=0.336$ & $\begin{array}{l}\text { VIGILANCE } \times \text { CONTEXT } \times \\
\text { GRID: } F(2 ; 104)=3.261 ; P=0.042\end{array}$ & $\begin{array}{l}\text { In the control condition for "grid" trials: } \\
\text { higher potentials for HPV compared with } \\
\text { LPV subjects }(P=0.04 \mathrm{I})\end{array}$ \\
\hline & & $\begin{array}{l}\text { VIGILANCE } \times \text { CONTEXT } \times \\
\text { ELECTRODE: } F(4 ; 208)=3.066 ; \\
P=0.027\end{array}$ & $\begin{array}{l}\text { In the control condition at Fz: higher } \\
\text { potentials for HPV compared with LPV } \\
\text { subjects }(P=0.002)\end{array}$ \\
\hline & & $\begin{array}{l}\text { VIGILANCE } \times \text { ELECTRODE } \times \\
\text { GRID: } F(2 ; 208)=4.128 ; P=0.031\end{array}$ & $\begin{array}{l}\text { For LPV subjects at Pz and Cz: higher } \\
\text { potentials in "grid" compared with "no- } \\
\text { grid" trials (both } P \text {-values }<0.0 \text { I) }\end{array}$ \\
\hline Late LPC & $F(I ; 104)=0.12 I ; P=0.729$ & all $F$ s $<1$ & - \\
\hline
\end{tabular}

Note: As for P200 and late LPC no significant interactive effects for VIGILANCE were found, no post-hoc testing for this factor was performed.

Abbreviations: EPN, early posterior negativity; ERP, event-related brain potential; LPC, late positive complex; LPV, low pain vigilant; HPV, high pain vigilant.

\section{Early LPC}

There were significant results for the main effect of the factors ELECTRODE and GRID as well as for their interaction (Table 4). Regarding the factor EMOTION, only a significant interaction effect between EMOTION and GRID was found (Table 4). Post hoc analyses of variance computed separately for the two categories of the factor GRID revealed a trend to a significant effect for the factor EMOTION only in the "grid" condition $(F[3 ; 327]=2.577 ; P=0.054)$ but not in the "no grid" condition $(F[3 ; 327]=1.701 ; P=0.167)$. To detail this trend to an emotion effect in the "grid" condition, post hoc $t$-tests for dependent samples were computed (Table 2). In the "grid" condition, anger and happy faces had lower potentials than neutral faces (for descriptive data, see Table 3).

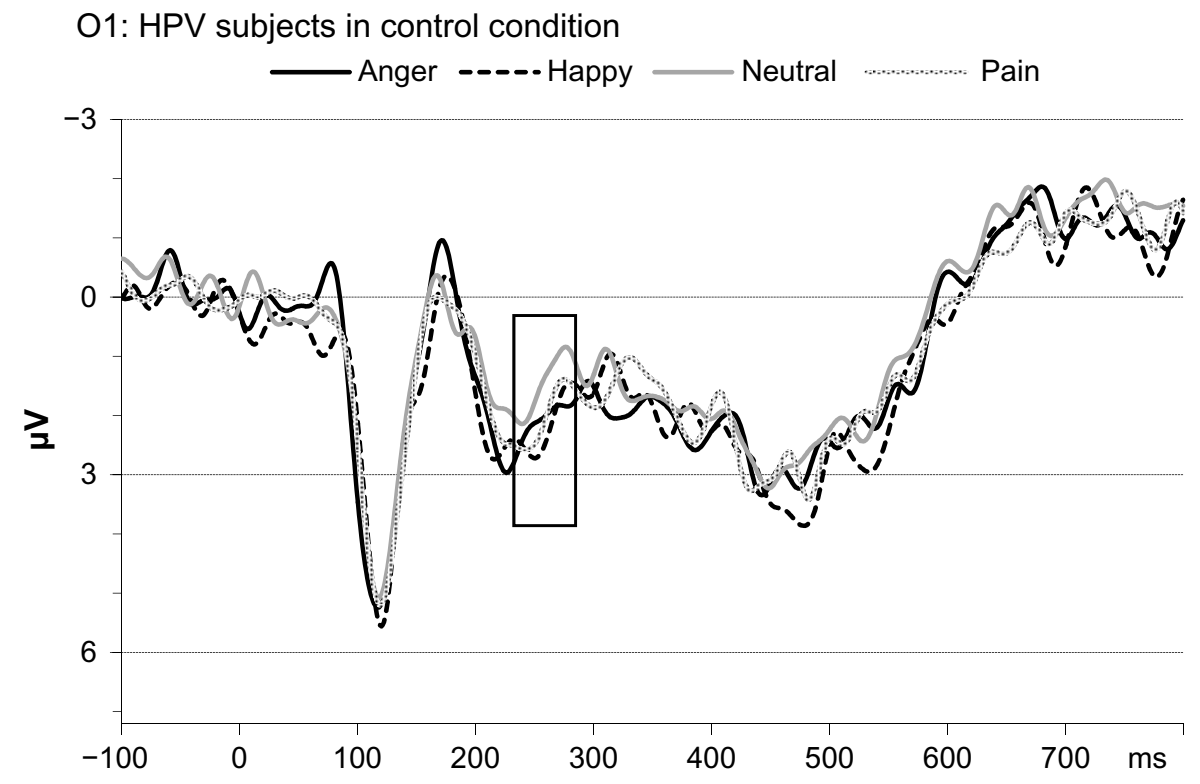

Figure 2 Grand averages for the four different categories of emotions at OI for HPV control subjects. Time window for EPN is marked by a frame. Abbreviations: EPN, early posterior negativity; HPV, high pain vigilant. 


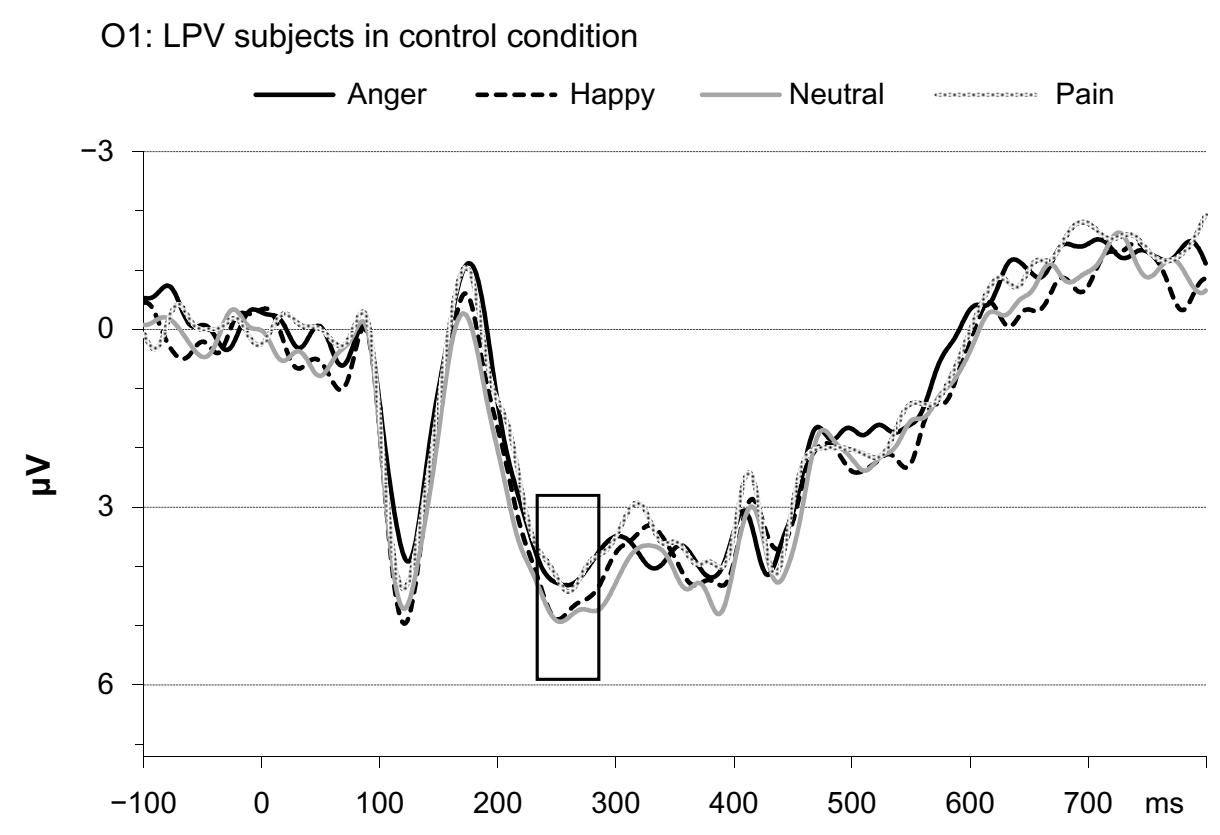

Figure 3 Grand averages for the four different categories of emotions at OI for LPV control subjects. Time window for EPN is marked by a frame. Abbreviations: EPN, early posterior negativity; LPV, low pain vigilant.

The between-subject factor VIGILANCE was included in three significant interaction effects: GRID $\times$ CONTEXT $\times$ VIGILANCE, ELECTRODE $\times$ CONTEXT $\times$ VIGILANCE, and GRID $\times$ ELECTRODE $\times$ VIGILANCE $($ Table 5). All three interactions including the factor, VIGILANCE, were subjected to further post hoc analyses (Table 5). The two interaction effects including the two between-subject factors CONTEXT and VIGILANCE revealed for both the control condition higher potentials of HPV compared with LPV subjects; this difference occurred either if only the "grid" condition was considered (HPV: $\mathrm{M}=3.11 \mu \mathrm{V}$; $\mathrm{SD}=1.74$; range: $0.91-7.18$; and $\mathrm{LPV}: \mathrm{M}=1.65 \mu \mathrm{V} ; \mathrm{SD}=2.11$; range: -1.20 to 5.75 ; Figures 4 and 5) or if only the electrode position $\mathrm{Fz}$ was considered (HPV: $\mathrm{M}=1.44 \mu \mathrm{V}$; $\mathrm{SD}=2.20$; range: -2.38 to 5.51 ; and $\mathrm{LPV}$ : $\mathrm{M}=-0.87 \mu \mathrm{V} ; \mathrm{SD}=1.93$; range: -4.57 to 2.97 ).

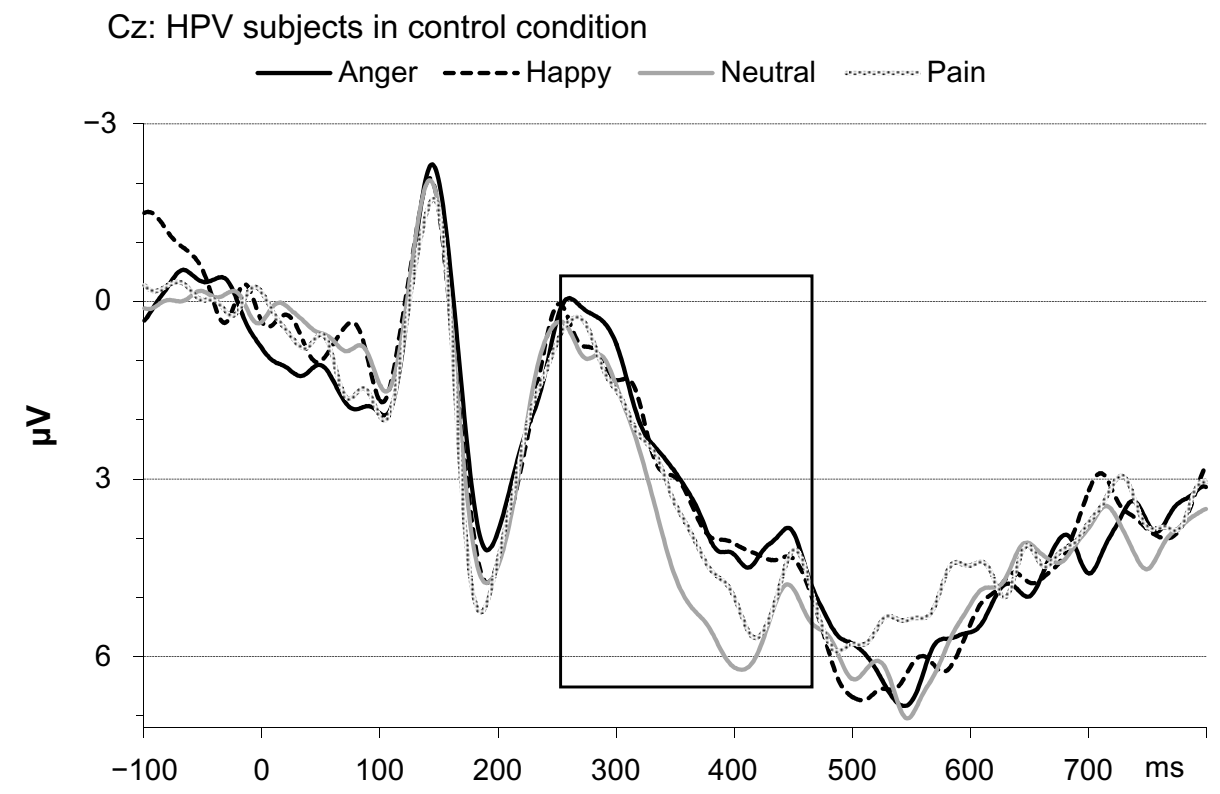

Figure 4 Grand averages for the four different categories of emotions at Cz for HPV control subjects for trials with "grid" presentation. Time window for early LPC is marked by a frame.

Abbreviations: HPV, high pain vigilant; LPC, late positive complex. 


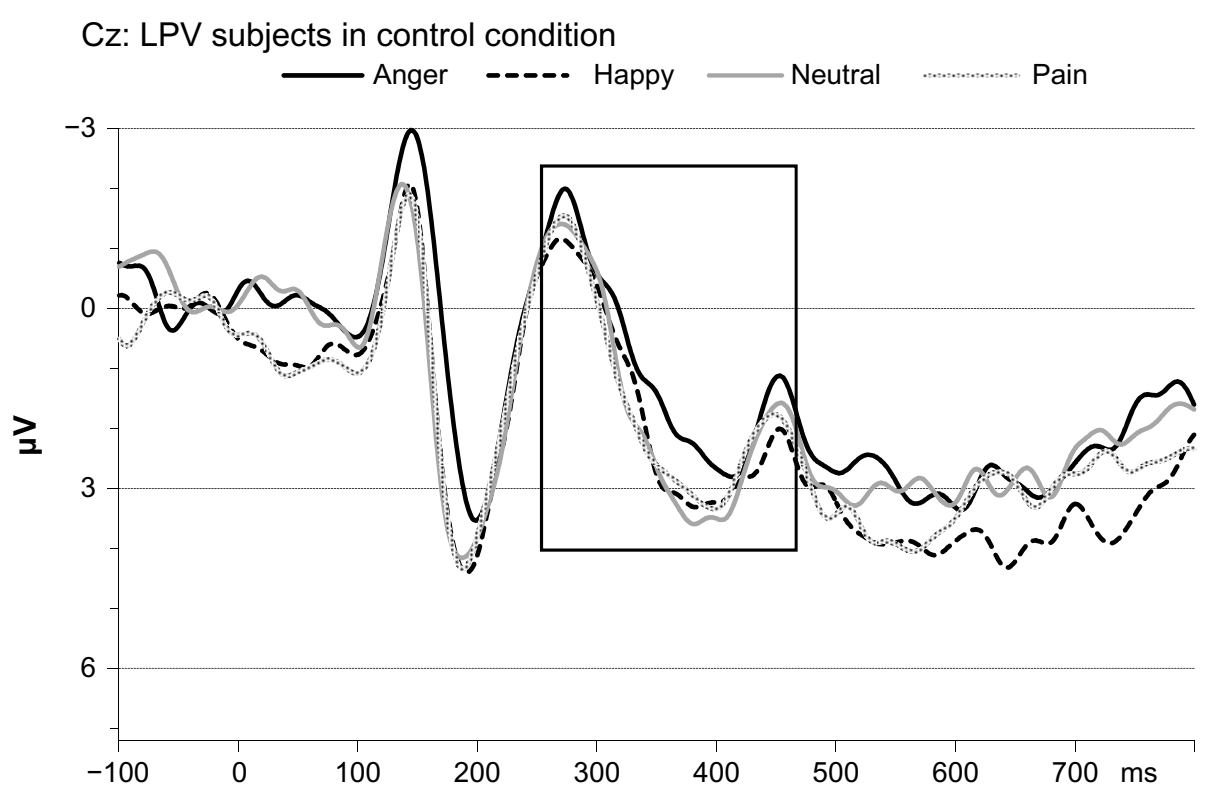

Figure 5 Grand averages for the four different categories of emotions at CZ for LPV control subjects for trials with "grid" presentation. Time window for early LPC is marked by a frame.

Abbreviations: LPV, low pain vigilant; LPC, late positive complex.

\section{Late LPC}

There were significant results for the main effects of the factors GRID and ELECTRODE as well as for their interaction (Table 4). There was also a significant interaction effect of EMOTION with the between-subject factor CONTEXT (Table 4). Post hoc analyses of variance computed separately for the three categories of the between-subject factor CONTEXT revealed a significant main effect of EMOTION in the "continuous threat" condition $(F[3 ; 108]=3.377 ; P=0.021)$, but not in the control condition $(F[3 ; 102]=2.265 ; P=0.085)$ or the "intermittent threat" condition $(F[3 ; 111]=1.299$; $P=0.279$ ). Results of post hoc $t$-tests for dependent samples for the "continuous threat" condition are shown in Table 2. For the "continuous threat" condition, anger faces had higher potentials than happy as well as neutral faces (see Table 3 for descriptive data).

\section{Summary}

Evidence for attentional processing of pain faces, which differs from processing of other emotional and neutral faces, could not be obtained. This lack of an effect was independent from the threat context. HPV compared with LPV subjects of the control condition showed an enhanced negativation for the EPN and increased potentials for the early LPC (occurring only for "grid" trials and at Fz) for the entire set of faces, including both emotional and neutral face expressions. This group difference between HPV and LPV individuals was visible only in the control condition and abolished by contextual threat through electro-stimulation. Effects of the various facial expressions of emotions on attentional processing became manifest for some ERP components. Activation for P300 and early LPC was diminished by anger and happy faces in the "grid" condition. The late LPC was increased by anger but only in the "continuous threat" condition. P100 potentials were decreased by pain, anger, and happy faces in the "grid" condition and only in LPV subjects.

\section{Discussion}

In the present study, we intended to examine how the attentional processing of pain-related cues (facial expression of pain) is determined by situational factors (ie, contextual threat) and individual predispositions regarding the vigilance to pain. For this purpose, we extended the paradigm used in a recent study of our group by a contextual threat induction (aversive electrical stimulation). ${ }^{16}$ Our data did not provide clear evidence for the main hypothesis that contextual threat increases the attentional capture by pain-related cues and that this effect is most prominent in individuals with high levels of vigilance to pain. However, the secondary hypothesis derived from our earlier study, assuming a generally enhanced attentional processing of emotional stimuli in persons with the tendency to pain hypervigilance, could be confirmed. This means that the findings of our previous study ${ }^{16}$ could partially be replicated. Furthermore, we could elaborate that this processing tendency in pain vigilant individuals 
already exists at early processing stages. We will discuss these findings more in detail below.

For explaining why our threat induction did not lead to a prioritized processing of pain faces or any of the other emotional facial expressions, it is relevant to scrutinize the design of our experimental paradigm including a primary task. A primary task paradigm was chosen in order to impede direct processing of the pain-related and emotional cues, which were deliberately made task irrelevant. We did this because of our understanding of hypervigilance. Pain-related cues should be salient enough to capture attention - at least in vigilant subjects - despite of their irrelevance for task solution. From our previous study, we knew already that the primary task (ie, detection of an overlaid "grid") is a strong competitor to processing task-irrelevant pain faces. ${ }^{16}$ Similarly, the "grid"-"no grid" differentiation made a strong impact on the reaction times and all ERP components in the present study. Therefore, it might be that the salience of the pain faces and also the other emotional faces might have been too small to counteract the task-relevant stimuli, leading to no major role of the face stimuli in attentional processing. Using black-and-white snap-shot pictures of the facial expressions of pain and other emotions may have reduced the cues' emotional salience; the alternative use of short colored video-clips, as done in other ERP studies, ${ }^{45,49}$ might have been advantageous regarding the emotional salience. We refrained from using such video-clips because they may produce higher risks as regards strict experimental control. In this sense, one might argue that it is not the high attentional load of the primary task alone that prevented effects of the facial expression of emotions but the limited emotional salience of the facial expressions.

One might have assumed that our successful induction of threat by use of aversive electrical stimulation should have changed the focus of attentional processing. Especially, the threat condition with intermittent electrical stimulation was clearly effective in producing sympathetic arousal. However, even in this condition pain faces did not gain much salience and had not distinct impacts on the ERP parameters considered. This means that for the attentional capture by emotional stimuli, such as pain faces, a fine-tuned balance must be established between the salience of these stimuli and other competing demands of the situation. Our experimental task might have missed to affect this balance with sufficient precision, and the effects of our threat manipulation were, therefore, not traceable.

We would like to address now the generally enhanced attentional processing of emotional stimuli, which were indicated by changes in EPN and early LPC. These ERP changes occurred, however, only in individuals with high levels of self-reported pain vigilance and replicated a finding from our previous study. ${ }^{16}$ In the present study the effect of enhanced processing was shown for the early LPC (mean activity for $260-460 \mathrm{~ms}$ after stimulus-onset), which is nearly equivalent to the P300 component (peak amplitude for 260-400 ms after stimulus-onset), which was the component suggesting this effect in our previous study. ${ }^{16}$ Further, this processing pattern was also indicated by EPN in the present study, a component that had not been assessed in our previous work. The EPN is regarded as the earliest indicator of differential emotional processing (for a review see Schupp et $\mathrm{a}^{150}$ ), and it has been described that the EPN increases as a function of the arousal of stimuli of both positive and negative valence. ${ }^{42,51}$ Therefore, our EPN finding supports the notion that in pain vigilant subjects the enhanced attentional capture is particularly driven by the emotional valence of stimuli. Similar effects for EPN and LPC elicited by threatening pictures have been reported before in a study comparing spider-phobic individuals with controls. ${ }^{52}$

Interestingly, the described effects in pain vigilant subjects were only manifest in the control condition and vanished as soon as contextual threat was added. The most-likely reason is that the aversive electrical stimuli were appraised as stimuli with a strong negative valence by pain vigilant subjects, who readily allocated in consequence their attentional resources away from the facial expression of pain toward the threat of physical pain. This phenomenon of a prioritized processing of stimuli with a strong threat value, such as impeding physical pain, as well as a disruption and a distraction away from the ongoing attentional processing by such stimuli have been described in the cognitive-affective model of the interruptive function of pain, ${ }^{53}$ and in the concept of hypervigilance to pain. ${ }^{1}$ It can be assumed that pain vigilant individuals always quickly attend to those stimuli holding the strongest threat value at a particular time point.

At last, it ought to be mentioned that a differentiation of pain faces from neutral faces could be accomplished only by use of the P100. However, this seemingly differential processing of pain faces was not specific because also the P100 elicited by anger and happy faces differed from the neutral category. Such a differential processing of emotional stimuli at an early stage of still reflex-like processing of visual input has already been observed before, ${ }^{37,43,47,54,55}$ but not with regard to pain as emotional content according to our knowledge.

Some limitations of our study should be named. Regarding our manipulation check it might have been helpful to assess state anxiety in addition to the assessment of autonomic threat responses and subjective experiences of the electrical 
stimuli (SSRs and VAS ratings). Since the trains of electrical stimulation were scheduled always at the identical time point within the trials, unwanted safety learning may have taken place, which might have been prevented by variation in the timing of stimulation. An alternative might be the usage of a verbal threat instruction, warning before post-experimental pain tests. ${ }^{17}$ Further, for better controlling the impact of the competition by the primary task, multiple tasks with a varying degree of task load should be run. ${ }^{37}$ Also, our primary task could be improved by asking for the discrimination of overlaid horizontal vs vertical lines, which would make the alternatives better comparable. Furthermore, it would be interesting to test individuals who are even more prone to attend to pain signals than the pain vigilant subjects in our study and might be found among individuals awaiting acute painful experiences/procedures or suffering from chronic pain. ${ }^{56}$

Summing up, in order to assess the effects of increased contextual threat on attentional processing of pain-cues, close attention must be paid to the choice of the experimental paradigm and stimulus material. The cognitive and motor demands of an applied primary task must be adjusted precisely to the salience of task-irrelevant but pain-related stimuli to establish a not one-sided competition for attention. Further, it can be inferred that pain vigilant subjects, when confronted with augmented contextual threat, do not stick to the pain-cues but quickly shift attention to other stimuli that hold the strongest threat value at a given time point.

The major contribution of the present study is the corroboration of previous evidence of enhanced attentional processing of all kinds of emotional and not only threatening stimuli in subjects describing themselves as pain vigilant. In addition, it was shown that this processing already occurs at relatively early processing stages, ie, before $300 \mathrm{~ms}$ after stimulus onset.

\section{Acknowledgment}

This study was supported by a research grant of the Deutsche Forschungsgemeinschaft (DFG LA 685/8-1).

\section{Disclosure}

The authors report no conflicts of interest in this work.

\section{References}

1. Crombez G, van Damme S, Eccleston C. Hypervigilance to pain: an experimental and clinical analysis. Pain. 2005;116(1-2):4-7.

2. Crombez G, Van Ryckeghem DM, Eccleston C, Van Damme S. Attentional bias to pain-related information: a meta-analysis. Pain. 2013; 154(4):497-510.
3. Lautenbacher S. Commentary to "do words hurt? brain activation during the processing of pain words' by Richter et al. Pain. 2010;148(2):179.

4. Keogh E, Ellery D, Hunt C, Hannent I. Selective attentional bias for pain-related stimuli amongst pain fearful individuals. Pain. 2001; 91(1-2):91-100.

5. Keogh E, Dillon C, Georgiou G, Hunt C. Selective attentional biases for physical threat in physical anxiety sensitivity. $J$ Anxiety Disord. 2001;15(4):299-315.

6. Asmundson GJ, Kuperos JL, Norton GR. Do patients with chronic pain selectively attend to pain-related information?: preliminary evidence for the mediating role of fear. Pain. 1997;72(1-2):27-32.

7. Asmundson GJ, Hadjistavropoulos HD. Is high fear of pain associated with attentional biases for pain-related or general threat? a categorical reanalysis. J Pain. 2007;8(1):11-18.

8. Roelofs J, Peters ML, Fassaert T, Vlaeyen JW. The role of fear of movement and injury in selective attentional processing in patients with chronic low back pain: a dot-probe evaluation. J Pain. 2005;6(5): 294-300.

9. Keogh E, Thompson T, Hannent I. Selective attentional bias, conscious awareness and the fear of pain. Pain. 2003;104(1-2):85-91.

10. Roelofs J, Peters ML, van der Zijden M, Thielen FG, Vlaeyen JW. Selective attention and avoidance of pain-related stimuli: a dot-probe evaluation in a pain-free population. J Pain. 2003;4(6): 322-328.

11. Khatibi A, Dehghani M, Sharpe L, Asmundson GJ, Pouretemad H. Selective attention towards painful faces among chronic pain patients: evidence from a modified version of the dot-probe. Pain. 2009;142(1-2): $42-47$.

12. Schoth DE, Liossi C. Attentional bias toward pictorial representations of pain in individuals with chronic headache. Clin J Pain. 2010;26(3): 244-250.

13. Baum C, Schneider R, Keogh E, Lautenbacher S. Different stages in attentional processing of facial expressions of pain: a dot-probe task modification. J Pain. 2013;14(3):223-232.

14. Nikendei C, Dengler W, Wiedemann G, Pauli P. Selective processing of pain-related word stimuli in subclinical depression as indicated by event-related brain potentials. Biol Psychol. 2005;70(1):52-60.

15. Dittmar O, Krehl R, Lautenbacher S. Interrelation of self-report, behavioural and electrophysiological measures assessing threat-related information processing. Pain Res Manag. 2011;16(1):33-40.

16. Lautenbacher S, Dittmar O, Baum C, Schneider R, Keogh E, Kunz M. Hypervigilance for pain-related faces in a primary task paradigm: an ERP study. J Pain Res. 2013;6:437-447.

17. Boston A, Sharpe L. The role of threat-expectancy in acute pain: effects on attentional bias, coping strategy effectiveness and response to pain. Pain. 2005;119(1-3):168-75.

18. Van Dessel P, Vogt J. When does hearing laughter draw attention to happy faces? Task relevance determines the influence of a crossmodal affective context on emotional attention. Front Hum Neurosci. 2012;6:294.

19. Flaisch T, Stockburger J, Schupp HT. Affective prime and target picture processing: an ERP analyses of early and late interference effects. Brain Topogr. 2008;20(4):183-191.

20. Wieser MJ, Pauli P, Reicherts P, Mühlberger A. Don't look at me in anger! enhanced processing of angry faces in anticipation of public speaking. Psychophysiology. 2010;47(2):271-280.

21. Juravle G, Stoeckel MC, Rose M, et al. Investigating the effect of respiratory bodily threat on the processing of emotional pictures. Respir Physiol Neurobiol. 2014;204:41-49.

22. Becker MW, Leinenger M. Attentional selection is biased toward mood-congruent stimuli. Emotion. 2011;11:1248-1254.

23. Grillon C, Ameli R, Woods SW, Merikangas K, Davis M. Fearpotentiated startle in humans: effects of anticipatory anxiety on the acoustic blink reflex. Psychophysiology. 1991;28(5):588-595.

24. Grillon C. Startle reactivity and anxiety disorders: aversive conditioning, context, and neurobiology. Biol Psychiatry. 2002;52: 958-975. 
25. First MB, Spitzer RL, Gibbon M, Williams JBW. Structured Clinical Interview for DSM-IV-TR Axis I Disorders, Research Version, Patient Edition with Psychotic Screen (SCID-I/P W/PSY SCREEN). New York: Biometrics Research, New York State Psychiatric Institute; 2002.

26. Grüter T, Grüter M, Bell V, Carbon CC. Visual mental imagery in congenital prosopagnosia. Neurosci Lett. 2009;453(3):135-140.

27. Simon D, Craig KD, Miltner WH, Rainville P. Brain responses to dynamic facial expressions of pain. Pain. 2006;126(1-3):309-318.

28. Baum C, Kappesser J, Schneider R, Lautenbacher S. Does vigilance to pain make person experts in facial recognition of pain? Pain Res Manag. 2013;18(4):191-196.

29. Lautenbacher S, Kunz M, Strate P, Nielsen J, Arendt-Nielsen L. Age effects on pain-thresholds, temporal summation and spatial summation of heat and pressure pain. Pain. 2005;115:410-418.

30. Lang PJ, Greenwald MK, Bradley MM, Hamm AO. Looking at pictures: affective, facial, visceral and behavioral reactions. Psychophysiology. 1993;30:261-273.

31. McCracken LM. 'Attention' to pain in persons with chronic pain: a behavioral approach. Behav Ther. 1997;28(2):271-284.

32. Jasper HH. The ten-twenty electrode system of the international federation. Electroencephalogr Clin Neurophysiol. 1958;10:370-375.

33. Gratton G, Coles MG, Donchin E. A new method for off-line removal of ocular artifact. Electroencephalogr Clin Neurophysiol. 1983; 55(4):468-484.

34. Picton TW, Bentin S, Berg P, et al. Guidelines for using human eventrelated potentials to study cognition: recording standards and publication criteria. Psychophysiology. 2000;37(2):127-152.

35. Miltner WH, Trippe RH, Krieschel S, Gutberlet I, Hecht H, Weiss T. Event-related brain potentials and affective responses to threat in spider/ snake-phobic and non-phobic subjects. Int J Psychophysiol. 2005;57(1): 43-52.

36. Schupp HT, Ohman A, Junghöfer M, Weike AI, Stockburger J, Hamm AO. The facilitated processing of threatening faces: an ERP analysis. Emotion. 2004;4(2):189-200.

37. Rellecke J, Sommer W, Schacht A. Does processing of emotional facial expressions depend on intention? Time-resolved evidence from eventrelated brain potentials. Biol Psychol. 2012;90(1):23-32.

38. Hajcak G, Nieuwenhuis S. Reappraisal modulates the electrocortical response to unpleasant pictures. Cogn Affect Behav Neurosci. 2006; 6(4):291-297.

39. Hajcak G, Olvet DM. The persistence of attention to emotion: brain potentials during and after picture presentation. Emotion. 2008;8(2): 250-255.

40. Leutgeb V, Schäfer A, Schienle A. Late cortical positivity and cardiac responsitivity in female dental phobics when exposed to phobia-relevant pictures. Int J Psychophysiol. 2011;79(3):410-416.

41. Moser JS, Hajcak G, Bukay E, Simons RF. Intentional modulation of emotional responding to unpleasant pictures: an ERP study. Psychophysiology. 2006;43(3):292-296.
42. Schupp HT, Junghöfer M, Weike AI, Hamm AO. The selective processing of briefly presented affective pictures: an ERP analysis. Psychophysiology. 2004;41(3):441-449.

43. Mühlberger A, Wieser MJ, Herrmann MJ, Weyers P, Tröger C, Pauli P. Early cortical processing of natural and artificial emotional faces differs between lower and higher socially anxious persons. J Neural Transm. 2009;116(6):735-746

44. Herrmann MJ, Aranda D, Ellgring H, et al. Face-specific eventrelated potential in humans is independent from facial expression. Int J Psychophysiol. 2002;45(3):241-244.

45. Gonzáles-Roldan AM, Martìnez-Jauand M, Muñoz-García MA, Sitges C, Cifre I, Montoya P. Temporal dissociation in the brain processing of pain and anger faces with different intensities of emotional expression. Pain. 2011;152(4):853-859.

46. Herrmann MJ, Ehlis AC, Ellgring H, Fallgatter AJ. Early stages (P100) of face perception in humans as measured with event-related potentials (ERPs). J Neural Transm. 2005;112(8):1073-1081.

47. Kolassa IT, Kolassa S, Musial F, Miltner HRW. Event-related brain potentials to schematic faces in social phobia. Cogn Emot. 2007;21(8): $1721-1744$

48. Sarlo M, Munafò M. When faces signal danger: event-related potentials to emotional facial expressions in animal phobics. Neuropsychobiology. 2010;62(4):235-244.

49. Reicherts P, Wieser MJ, Gerdes AB, et al. Electrocortical evidence for preferential processing of dynamic pain expressions compared to other emotional expressions. Pain. 2012;153(9):1959-1964.

50. Schupp HT, Flaisch T, Stockburger J, Junghöfer M. Emotion and attention: event-related brain potential studies. In: Anders S, Ende G, Junghöfer M, Kissler J, Wildgruber D, editors. Progress in Brain Research. Amsterdam: Elsevier; 2006:31-51.

51. Junghöfer M, Bradley MM, Elbert TR, Lang PJ. Fleeting images: a new look at early emotion discrimination. Psychophysiology. 2001;38: 175-178.

52. Michalowski JM, Melzig CA, Weike AI, Stockburger J, Schupp HT, Hamm AO. Brain dynamics in spider-phobic individuals exposed to phobia-relevant and other emotional stimuli. Emotion. 2009;9(3): 306-315.

53. Eccleston C, Cormbez G. Pain demands attention: a cognitive-affective model of the interruptive function of pain. Psychol Bull. 1999;125(3): 356-366.

54. Kolassa IT, Buchmann A, Lauche R, et al. Spider phobics more easily see a spider in morphed schematic pictures. Behav Brain Funct. 2007;3:59.

55. Weinberg A, Hajcak G. Electrocortical evidence for vigilanceavoidance in generalized anxiety disorder. Psychophysiology. 2011;48: $842-851$.

56. Sitges C, García-Herrera M, Pericás M, Collado D, Truyols M, Montoya P. Abnormal brain processing of affective and sensory pain descriptors in chronic pain patients. J Affect Disord. 2007;104(1-3):73-82.
Journal of Pain Research

\section{Publish your work in this journal}

The Journal of Pain Research is an international, peer-reviewed, open access, online journal that welcomes laboratory and clinical findings in the fields of pain research and the prevention and management of pain. Original research, reviews, symposium reports, hypothesis formation and commentaries are all considered for publication.

\section{Dovepress}

The manuscript management system is completely online and includes a very quick and fair peer-review system, which is all easy to use. Visit http://www.dovepress.com/testimonials.php to read real quotes from published authors. 